\title{
Chronological Evaluation of the Onset of Histologically Confirmed Interstitial Pneumonia Associated with Polymyositis/dermatomyositis
}

\author{
Yu YANG*, Jiro FustTa, Michiaki Tokuda, Shuji BandoH and Toshihiko IsHida
}

\begin{abstract}
Objective The present study was designed to determine the chronological sequence of interstitial pneumonia, skin involvement, and muscle involvement associated with polymyositis/dermatomyositis (PM/DM).

Methods We examined our own cases of histologically confirmed interstitial pneumonia associated with PM/DM. In addition, a review of the literature was done to evaluate other cases of histologically confirmed interstitial pneumonia associated with PM/DM. Lung involvement was the first clinical symptom for all of our 8 patients.

Results Including the literature review and our 8 cases, there were 94 patients with PM/DM in whom interstitial pneumonia was histologically confirmed (36 PM, $50 \mathrm{DM}$, and 8 amyopathic DM). Chronological evaluation between the diagnosis of PM/DM and lung involvement demonstrated that most lung involvement occurred just before or just after the diagnosis of PM/DM. Interstitial pneumonia was preceded in 35 of 87 evaluable patients [ 21 cases with PM $(61.8 \%), 14$ cases with DM and amyopathic DM $(40.2 \%)]$. In 60 of 87 evaluable patients $(69.0 \%)$, lung involvement occurred as a clinical manifestation at the diagnosis of PM/DM.
\end{abstract}

Conclusion The present data demonstrate that interstitial pneumonia was frequently the initial onset in patients with PM/DM.

(Internal Medicine 41: 1135-1141, 2002)

Key words: surgical lung biopsy, pathology, pulmonary fibrosis

\section{Introduction}

Interstitial lung involvement occurring in polymyositis/der- matomyositis (PM/DM) was first described by Mills and Matthews in 1956 (1). Since then, various retrospective studies have described the relationship between PM/DM and diffuse interstitial lung disease (1-50). Tazelaar et al (22) reviewed specimens obtained at open lung biopsy from 14 patients with PM/DM and at autopsy from 1 patient, and reported 4 major groups based on the histologic patterns: bronchiolitis obliterans organizing pneumonia (BOOP), usual interstitial pneumonia (UIP), acute interstitial pneumonia (AIP), and cellular interstitial pneumonia (CIP). More recently, Katzenstein and Fiorelli (51) reported that 10 of their 64 patients with non-specific interstitial pneumonia (NSIP) had an association with connective tissue diseases, including two patients with PM. As it has been reported that interstitial lung disease affects the prognosis of PM/DM, and the prognosis of interstitial lung disease differs according to the histological findings (22), it is therefore important to evaluate the pathological types of interstitial lung disease. In addition, we believe that it is very important to evaluate the onset of lung involvement in relation to skin involvement and/or muscle involvement.

Considering this background, we evaluated the chronological sequence of the onset of interstitial pneumonia and compared that with the onset of skin lesions and/or muscle lesions.

\section{Materials and Methods}

\section{Subjects}

We first examined our own patients with a diagnosis of PM/ DM (Table 1). PM/DM was diagnosed according to the criteria of Bohan and Peter (52) and Dalakas (53), and classified according to the criteria described by Tanimoto et al (54): (i) symmetric muscle weakness; (ii) typical histologic findings on muscle biopsy; (iii) increased levels of muscle enzymes in the sera; (iv) compatible electromyographic findings; and (v) characteristic dermatologic manifestations. The typical skin involvement of DM was confirmed when either Gottron's papules or heliotrope rash were identified. Other cutaneous lesions (e.g.,

From the First Department of Internal Medicine, Kagawa Medical University, Kagawa, *the Department of Rheumatology and Immunology, First Clinical College, China Medical University

Received for publication January 7, 2002; Accepted for publication September 7, 2002

Reprint requests should be addressed to Dr. Jiro Fujita, the First Department of Internal Medicine, Kagawa Medical University, 1750-1 Miki-cho, Kita-gun, Kagawa 761-0793 
YANG et al

Table 1. Clinical Features of Patients with Interstitial Pneumonia Associated with Polymyositis/dermatomyositis

\begin{tabular}{|c|c|c|c|c|c|c|c|c|}
\hline Case & Authors & References & $\begin{array}{l}\text { Age \& } \\
\text { Sex }\end{array}$ & $\begin{array}{c}\text { Clinical } \\
\text { Diagnoses* }\end{array}$ & $\begin{array}{c}\text { First } \\
\text { Symptom }^{+}\end{array}$ & $\begin{array}{c}\text { Intervals }^{++} \\
\text {(Months) }\end{array}$ & $\begin{array}{c}\text { Lung } \\
\text { Specimens }^{\S}\end{array}$ & Outcome \\
\hline 1 & Mills & 1 & $52 \mathrm{~F}$ & DM & $\mathrm{L}$ & -4 & Autopsy & Dead \\
\hline 2 & Goldfischer & 2 & $62 \mathrm{M}$ & DM & $\mathrm{S}$ & 3 & SLB & Dead \\
\hline 3 & Hyun & 3 & $57 \mathrm{~F}$ & DM & $\mathrm{L}$ & 0 & Autopsy & Dead \\
\hline 4 & Sandbank & 4 & $55 \mathrm{~F}$ & DM & M & 12 & Autopsy & Dead \\
\hline 5 & Weaver & 5 & $40 \mathrm{~F}$ & DM & $\mathrm{L}+\mathrm{S}$ & 0 & SLB & Alive \\
\hline 6 & Thompson & 6 & $60 \mathrm{~F}$ & PM & $\mathrm{L}$ & -3 & SLB & Dead \\
\hline 7 & Thompson & 6 & $60 \mathrm{M}$ & PM & $\mathrm{L}+\mathrm{M}$ & 0 & Autopsy & Dead \\
\hline 8 & Olsen & 7 & $48 \mathrm{~F}$ & $\mathrm{PM}$ & $\mathrm{L}+\mathrm{M}$ & 0 & SLB & Alive \\
\hline 9 & " & 7 & $37 \mathrm{~F}$ & PM & M & 12 & SLB & Alive \\
\hline 10 & Webb & 8 & $65 \mathrm{M}$ & PM & $\mathrm{L}$ & -1 & SLB & Alive \\
\hline 11 & Duncan & 9 & $44 \mathrm{~F}$ & DM & $\mathrm{L}+\mathrm{M}+\mathrm{S}$ & 0 & SLB & Alive \\
\hline 12 & $"$ & 9 & $39 \mathrm{~F}$ & PM & L & -2 & Autopsy & Dead \\
\hline 13 & Krain & 10 & $44 \mathrm{M}$ & DM & $\mathrm{L}+\mathrm{M}+\mathrm{S}$ & 0 & SLB & Alive \\
\hline 14 & Schwarz & 11 & $37 \mathrm{M}$ & DM & $\mathrm{L}$ & -3 & SLB & Alive \\
\hline 15 & " & 11 & $32 \mathrm{~F}$ & PM & M & 24 & Autopsy & Dead \\
\hline 16 & $"$ & 11 & $61 \mathrm{~F}$ & PM & $\mathrm{L}$ & -24 & SLB & Alive \\
\hline 17 & " & 11 & $51 \mathrm{~F}$ & PM & $\mathrm{L}$ & -1 & Autopsy & Dead \\
\hline 18 & $"$ & 11 & $60 \mathrm{M}$ & PM & $\mathrm{L}$ & -3 & Autopsy & Dead \\
\hline 19 & $"$ & 11 & $64 \mathrm{~F}$ & PM & M & 5 & SLB & Alive \\
\hline 20 & Plowman & 12 & $29 \mathrm{M}$ & DM & $\mathrm{M}+\mathrm{S}$ & 1 & SLB & Alive \\
\hline 21 & Fernandes & 13 & $48 \mathrm{M}$ & Amyopathic DM & $\mathrm{S}$ & 9 & Autopsy & Dead \\
\hline 22 & Hanawa & 14 & $46 \mathrm{~F}$ & PM & $\mathrm{L}$ & -12 & SLB & Alive \\
\hline 23 & Fergusson & 15 & $58 \mathrm{M}$ & $\mathrm{DM}$ & $\mathrm{S}$ & 1 & Autopsy & Dead \\
\hline 24 & " & 15 & $76 \mathrm{~F}$ & $\mathrm{DM}$ & $\mathrm{L}+\mathrm{M}+\mathrm{S}$ & 0 & Autopsy & Dead \\
\hline 25 & Schiavi & 16 & $24 \mathrm{~F}$ & $\mathrm{DM}$ & $\mathrm{L}$ & -4 & SLB & Alive \\
\hline 26 & Wasicek & 17 & $59 \mathrm{M}$ & PM & $\mathrm{L}+\mathrm{M}$ & 0 & SLB & Dead \\
\hline 27 & Fudman & 18 & $42 \mathrm{~F}$ & Amyopathic DM & $\mathrm{S}$ & 1 & TBLB & Dead \\
\hline 28 & $"$ & 18 & $55 \mathrm{~F}$ & Amyopathic DM & $\mathrm{L}+\mathrm{S}$ & 0 & TBLB & Dead \\
\hline 29 & Gruhn & 19 & $34 \mathrm{~F}$ & $\mathrm{DM}$ & $\mathrm{L}+\mathrm{M}$ & 0 & TBLB & Alive \\
\hline 30 & Takizawa & 20 & $54 \mathrm{~F}$ & DM & $\mathrm{S}$ & 3 & Autopsy & Dead \\
\hline 31 & " & 20 & $50 \mathrm{~F}$ & DM & $\mathrm{L}+\mathrm{M}+\mathrm{S}$ & 0 & TBLB & Dead \\
\hline 32 & $"$ & 20 & $53 \mathrm{M}$ & $\mathrm{DM}$ & $\mathrm{L}$ & -2 & TBLB & Alive \\
\hline 33 & Kobayashi & 21 & $49 \mathrm{~F}$ & $\mathrm{DM}$ & $\mathrm{S}$ & 4 & Autopsy & Dead \\
\hline 34 & Tazelaar & 22 & $47 \mathrm{~F}$ & PM & $\mathrm{L}+\mathrm{M}$ & 0 & SLB & Alive \\
\hline 35 & $"$ & 22 & $53 \mathrm{~F}$ & PM & $\mathrm{L}+\mathrm{M}$ & 0 & SLB & Alive \\
\hline 36 & " & 22 & $19 \mathrm{~F}$ & $\mathrm{DM}$ & $\mathrm{L}$ & -1 & SLB & Dead \\
\hline 37 & $"$ & 22 & $31 \mathrm{M}$ & PM & $\mathrm{L}+\mathrm{M}$ & 0 & SLB & Alive \\
\hline 38 & $"$ & 22 & $32 \mathrm{~F}$ & DM & $\mathrm{M}+\mathrm{S}$ & 2 & SLB & Dead \\
\hline 39 & $"$ & 22 & $73 \mathrm{M}$ & PM & $\mathrm{L}$ & -6 & SLB & Alive \\
\hline 40 & $"$ & 22 & $57 \mathrm{~F}$ & DM & $\mathrm{M}+\mathrm{S}$ & 36 & SLB & Alive \\
\hline 41 & " & 22 & $55 \mathrm{~F}$ & DM & $\mathrm{M}+\mathrm{S}$ & 6 & SLB & Dead \\
\hline 42 & " & 22 & $72 \mathrm{~F}$ & PM & $\mathrm{L}+\mathrm{M}$ & 0 & SLB & Dead \\
\hline 43 & " & 22 & $61 \mathrm{M}$ & $\mathrm{DM}$ & $\mathrm{M}+\mathrm{S}$ & 3 & SLB & Dead \\
\hline 44 & " & 22 & $40 \mathrm{M}$ & DM & $\mathrm{S}$ & 0 & SLB & Alive \\
\hline 45 & " & 22 & $57 \mathrm{M}$ & $\mathrm{DM}$ & $\mathrm{L}+\mathrm{M}+\mathrm{S}$ & 0 & SLB & Dead \\
\hline 46 & " & 22 & $67 \mathrm{~F}$ & DM & $\mathrm{L}+\mathrm{M}+\mathrm{S}$ & 0 & SLB & Dead \\
\hline 47 & " & 22 & $41 \mathrm{M}$ & $\mathrm{DM}$ & $\mathrm{M}+\mathrm{S}$ & 1 & SLB & Dead \\
\hline 48 & $"$ & 22 & $58 \mathrm{~F}$ & PM & $\mathrm{L}+\mathrm{M}$ & 0 & SLB & Dead \\
\hline 49 & Tokiyama & 23 & $55 \mathrm{~F}$ & Amyopathic DM & $S$ & 5 & Autopsy & Dead \\
\hline 50 & $"$ & 23 & $46 \mathrm{~F}$ & Amyopathic DM & $\mathrm{S}$ & 11 & Autopsy & Dead \\
\hline 51 & Lambie & 24 & $19 \mathrm{M}$ & $\mathrm{PM}$ & $\mathrm{L}$ & -1 & TBLB & Alive \\
\hline 52 & Mahler & 25 & $65 \mathrm{~F}$ & PM & $\mathrm{L}+\mathrm{M}$ & 0 & TBLB & Alive \\
\hline 53 & Imokawa & 26 & $58 \mathrm{~F}$ & PM & $\mathrm{L}$ & -4 & SLB & Alive \\
\hline 54 & Hsue & 27 & $36 \mathrm{~F}$ & PM & $\mathrm{L}$ & -10 & SLB & Alive \\
\hline 55 & Lohr & 28 & 67 & PM & $\mathrm{L}$ & -10 & TBLB & Alive \\
\hline
\end{tabular}


Interstitial Pneumonia in PM/DM

\begin{tabular}{|c|c|c|c|c|c|c|c|c|}
\hline 56 & Mouri & 29 & $60 \mathrm{~F}$ & DM & $\mathrm{L}$ & -2 & SLB & Alive \\
\hline 57 & Clawson & 30 & $47 \mathrm{~F}$ & PM & $\mathrm{L}+\mathrm{M}$ & 0 & Autopsy & Dead \\
\hline 58 & " & 30 & $40 \mathrm{~F}$ & PM & M & 6 & SLB & Dead \\
\hline 59 & de Toro Santos & 31 & $41 \mathrm{~F}$ & $\mathrm{DM}$ & $\mathrm{M}+\mathrm{S}$ & 4 & SLB & Dead \\
\hline 60 & Ozawa & 32 & $48 \mathrm{~F}$ & DM & $\mathrm{M}+\mathrm{S}$ & 5 & Autopsy & Dead \\
\hline 61 & Nagai & 33 & $69 \mathrm{~F}$ & PM & $\mathrm{L}+\mathrm{M}$ & 0 & TBLB & Alive \\
\hline 62 & Grau & 34 & $64 \mathrm{M}$ & DM & $\mathrm{M}+\mathrm{S}$ & 3 & SLB & Alive \\
\hline 63 & " & 34 & $52 \mathrm{~F}$ & DM & $\mathrm{L}+\mathrm{M}+\mathrm{S}$ & 0 & SLB & Alive \\
\hline 64 & " & 34 & $59 \mathrm{~F}$ & $\mathrm{DM}$ & $\mathrm{L}+\mathrm{S}$ & 0 & SLB & Alive \\
\hline 65 & Ikuta & 35 & $61 \mathrm{~F}$ & PM & $\mathrm{L}$ & -1 & SLB & Alive \\
\hline 66 & Fata & 36 & $51 \mathrm{M}$ & PM & $\mathrm{L}$ & -2 & SLB & Alive \\
\hline 67 & Kalenian & 37 & $53 \mathrm{M}$ & DM & $\mathrm{L}+\mathrm{M}$ & 0 & SLB & Alive \\
\hline 68 & Shinohara & 38 & $56 \mathrm{~F}$ & $\mathrm{DM}$ & $\mathrm{L}$ & 0 & SLB & Alive \\
\hline 69 & Asanuma & 39 & $48 \mathrm{~F}$ & Amyopathic DM & $S$ & 12 & SLB & Alive \\
\hline 70 & Kiely & 40 & $66 \mathrm{M}$ & $\mathrm{PM}$ & $\mathrm{L}$ & -6 & SLB & Alive \\
\hline 71 & Nobutoh & 41 & $47 \mathrm{~F}$ & DM & $\mathrm{L}$ & -3 & Autopsy & Dead \\
\hline 72 & Satoh & 42 & $62 \mathrm{M}$ & PM & $\mathrm{L}$ & -3 & TBLB & Alive \\
\hline 73 & Satomi & 43 & $59 \mathrm{~F}$ & $\mathrm{DM}$ & $\mathrm{M}+\mathrm{S}$ & 3 & TBLB & Alive \\
\hline 74 & Takahashi & 44 & $56 \mathrm{M}$ & PM & $\mathrm{L}$ & -3 & TBLB & Alive \\
\hline 75 & Ito & 45 & $41 \mathrm{M}$ & DM & Unclear & 1 & Autopsy & Dead \\
\hline 76 & " & 45 & $49 \mathrm{~F}$ & DM & Unclear & 3 & Autopsy & Dead \\
\hline 77 & " & 45 & $43 \mathrm{M}$ & DM & Unclear & 1 & Autopsy & Dead \\
\hline 78 & " & 45 & $61 \mathrm{~F}$ & $\mathrm{DM}$ & Unclear & 2 & Autopsy & Dead \\
\hline 79 & " & 45 & $58 \mathrm{~F}$ & DM & Unclear & 1 & Autopsy & Dead \\
\hline 80 & " & 45 & $26 \mathrm{~F}$ & $\mathrm{DM}$ & Unclear & 4 & Autopsy & Dead \\
\hline 81 & $"$ & 45 & $34 \mathrm{M}$ & DM & Unclear & 0 & Autopsy & Dead \\
\hline 82 & Itoh & 46 & $44 \mathrm{~F}$ & $\mathrm{DM}$ & $\mathrm{S}$ & 2 & TBLB & Alive \\
\hline 83 & Knoell & 47 & $44 \mathrm{~F}$ & $\mathrm{DM}$ & $\mathrm{L}$ & -2 & SLB & Alive \\
\hline 84 & Takashi & 48 & $42 \mathrm{M}$ & Amyopathic DM & $\mathrm{L}+\mathrm{S}$ & 0 & SLB & Alive \\
\hline 85 & Lee & 49 & $46 \mathrm{~F}$ & $\mathrm{DM}$ & $\mathrm{S}$ & 3 & SLB & Alive \\
\hline 86 & Nanke & 50 & $53 \mathrm{M}$ & Amyopathic DM & $\mathrm{L}+\mathrm{S}$ & 0 & Autopsy & Dead \\
\hline 87 & Present study & - & $58 \mathrm{M}$ & $\mathrm{DM}$ & $\mathrm{L}$ & -24 & SLB & Dead \\
\hline 88 & " - & - & $70 \mathrm{~F}$ & $\mathrm{DM}$ & $\mathrm{L}$ & -2 & SLB & Dead \\
\hline 89 & " & - & $65 \mathrm{~F}$ & PM & $\mathrm{L}$ & -7 & SLB & Alive \\
\hline 90 & " & - & $56 \mathrm{~F}$ & $\mathrm{DM}$ & $\mathrm{L}$ & -3 & SLB & Alive \\
\hline 91 & " & - & $60 \mathrm{~F}$ & PM & $\mathrm{L}$ & -3 & SLB & Alive \\
\hline 92 & " & - & $57 \mathrm{M}$ & PM & $\mathrm{L}$ & -1 & SLB & Alive \\
\hline 93 & " & - & $45 \mathrm{~F}$ & $\mathrm{DM}$ & $\mathrm{L}$ & -6 & SLB & Alive \\
\hline 94 & " & - & $63 \mathrm{~F}$ & PM & $\mathrm{L}$ & -12 & SLB & Alive \\
\hline
\end{tabular}

*PM: polymyositis, DM: dermatomyositis, ${ }^{+} \mathrm{L}$ : lung (interstitial pneumonia), M: muscle involvement, S: skin lesions. ${ }^{++}$Interval: months from the diagnosis of polymyositis/dermatomyositis to the onset of interstitial pneumonia. ${ }^{\S}$ SLB: surgical lung biopsy, TBLB: transbronchial lung biopsy.

mechanical hands, cuticular hyperplasia, or sun related erythema) were also considered to be skin involvement of DM (52).

The median age of our 8 patients with PM/DM was 59.3 years old with a range of 45 to 70 years ( 2 males and 6 females). The diagnoses of interstitial pneumonia were made on clinical, radiological, physiological, and histological grounds. The criteria used included: history of exertional dyspnea and cough, fine crackles on physical examination, compatible findings on the chest radiograph, physiologic abnormalities of restrictive lung defects including decreased diffusing capacity, and abnormal $\mathrm{PaO} 2$ at rest and/or with exertion. In all patients, high resolution computed radiographic scanning of the lungs was performed. Histological confirmation was obtained by open lung biopsy ( 6 cases) or autopsy ( 2 cases). No patients received immunosuppressive treatment such as corticosteroid or cyclophosphamide at the time of open lung biopsy. The histology of 6 patients with interstitial pneumonia associated with PM/DM had the pattern of NSIP according to the criteria described by Katzenstein and Fiorelli (51). Two patients fulfilled the clinical and pathologic criteria of AIP as described by Katzenstein et al (55).

\section{Literature Review}

In addition to our 8 cases with histologically confirmed interstitial pneumonia, we reviewed case reports concerning PM/ DM associated with interstitial pneumonia through MEDLINE. Articles not listed in MEDLINE and those written in languages other than English or Japanese were excluded.

There are seven subsets of myositis $(53,54)$ : DM, PM, myo- 
sitis with cancer, childhood PM and DM, myositis overlapping with another collagen-vascular disorder, amyopathic DM (56), and inclusion-body myositis (57). Among them, cases with myositis with cancer, childhood PM (age less than 16), myositis overlapping with another collagen-vascular disorder, or inclusion-body myositis were excluded.

Since pulmonary complications associated with PM/DM were heterogeneous (for example aspiration pneumonia or opportunistic infections), patients without histological confirmation of interstitial pneumonia were also excluded. In addition, patients whose clinical description was inadequate for evaluating the chronological sequence of the onset of interstitial pneumonia were also excluded.

Finally, including the present 8 cases, 94 cases (1-50) were reviewed (Table 1) to evaluate the chronological sequence of interstitial pneumonia. The diagnosis of interstitial pneumonia was made by surgical lung biopsy in 55 cases, autopsy in 26 cases, and transbronchial lung biopsy in 13 cases.

\section{Criteria for the Onset of Interstitial Pneumonia, Skin Lesions, and Muscle Involvement}

Since all cases were histologically confirmed to be interstitial pneumonia, it is reasonable to assume that the respiratory symptoms were caused by interstitial pneumonia. However, to be more precise, the following criteria were used. As for clinical symptoms, cough as well as dyspnea were considered to represent the onset of interstitial pneumonia. Cough, sputum, or chest pain, as a single symptom was not considered to indicate the onset of interstitial pneumonia. Chest X-ray or chest CT abnormality compatible with interstitial pneumonia was considered to indicate the onset of interstitial pneumonia.

Skin rashes typical or compatible with DM as described previously were considered as the onset of skin lesions in patients with DM or amyopathic DM. Progressive, proximal, generalized weakness and/or myalgia were considered as the onset of myositis in patients with PM/DM. An increased concentration of muscle enzymes and/or abnormalities in electromyogram was also considered to indicate the existence of myositis in PM/DM and amyopathic DM.

\section{Results}

In all of the present 8 patients, lung involvement was the first clinical symptom of onset (Fig. 1). With the literature review and our 8 cases, there were 94 patients with PM/DM in whom interstitial pneumonia was histologically confirmed (36 PM, 50 DM, and 8 amyopathic DM) (Table 2). There were 62 females, 31 males, and 1 non-described.

In total, anti-Jo-1 antibody was positive in 17 of $40(42.5 \%)$ described cases (among the 94 cases, the results of anti-Joantibody were not described in 54 cases). In the present cases, rheumatoid factor was detected in case \#88 and case \#91 (case numbers are as listed in Table 1). Anti-nuclear antibody was detected in case 91, case 92, and case 93. Anti-Jo-1 antibody was detected in case 90 and case 94 .

Methods of lung biopsy, pathological classifications, and

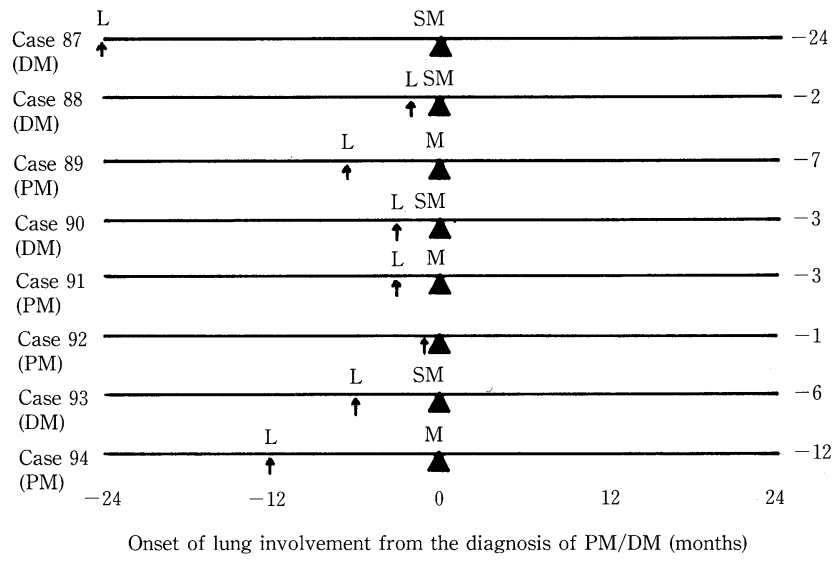

Figure 1. Chronological evaluation of the onset of interstitial pneumonia, skin lesions, and/or the muscle involvement in the present 8 patients with polymyositis/dermatomyositis (PM/DM). L: lung lesions, S: skin lesions, M: muscle involvement. Arrow: onset of lung lesions in our 8 cases. Triangle: at the time of clinical diagnosis of PM/DM. Numbers of vertical axis: months from the diagnosis of PM/DM (triangle) to the onset of interstitial pneumonia (arrow). In all 8 patients with polymyositis/dermatomyositis, interstitial pneumonia was observed as the initial onset of clinical symptoms of PM/DM.

outcome are also listed in Table 2. Since definite pathological classification had not been established previously, we simply classified those cases (pathological classification could not be evaluated) as pulmonary (interstitial) fibrosis. About one-half of the patients died of respiratory failure due to interstitial pneumonia.

The chronological evaluation between the onset of interstitial pneumonia and the onset of skin lesions or muscle lesions are listed in Table 2 and also shown in Fig. 2. Chronological evaluation between the onset of PM/DM and lung involvement demonstrated that most lung involvement occurred just before or just after the onset of PM/DM (Fig. 2). Interstitial pneumonia was preceded in 35 of 87 patients (21 cases with PM and 14 cases with DM [40.2\%, Table 3]). In 60 of 87 patients (69.0\%, including the 35 preceding cases), lung involvement was observed at the onset of PM/DM. In addition, skin involvement was observed at the onset of DM and amyopathic DM in 34 patients $(39.1 \%)$ and muscle involvement was observed at the onset of PM/DM in 35 patients (40.2\%), respectively.

Although interstitial pneumonia tended to be the initial onset more frequently in cases diagnosed by chest CT compared with cases diagnosed by chest X-ray only, there were no significant statistical differences between the 2 groups $(\mathrm{p}=0.1096$, $\chi$-square test).

\section{Discussion}

PM/DM.are multisystem disorders of unknown cause which occur in all age groups, but predominate in mid-adult life and 
Table 2. Patient Characteritics (Total 94 Patients)

\begin{tabular}{lcc}
\hline & Age (Median [range]) & Case number (Female/Male/Undescribed) \\
PM & $58[19-73]$ & $36(23 / 12 / 1)$ \\
DM & $51[19-76]$ & $50(34 / 16 / 0)$ \\
Amyopathic DM & $48[46-55]$ & $8(5 / 3 / 0)$ \\
Methods of histological evaluation & \\
Surgical lung biopsy & 55 \\
TBLB* & 13 \\
Autopsy & 26 \\
Pathological classification ${ }^{+}$ & \\
Pulmonary (interstitial) fibrosis & \\
BOOP & 32 \\
DAD & 18 \\
NSIP & 18 \\
UIP & 8 \\
DIP & 5 \\
Undetermined (TBLB cases) & 1 \\
Outcome & 12 \\
Alive & \\
Dead & \\
\hline
\end{tabular}

*TBLB: transbronchial lung biopsy, ${ }^{+}$BOOP: bronchiolitis obliterans organizing pneumonia, DAD: diffuse alveolar damage, NSIP: non-specific interstitial pneumonia, UIP: usual interstitial pneumonia, DIP: desquamative interstitial pneumonia.

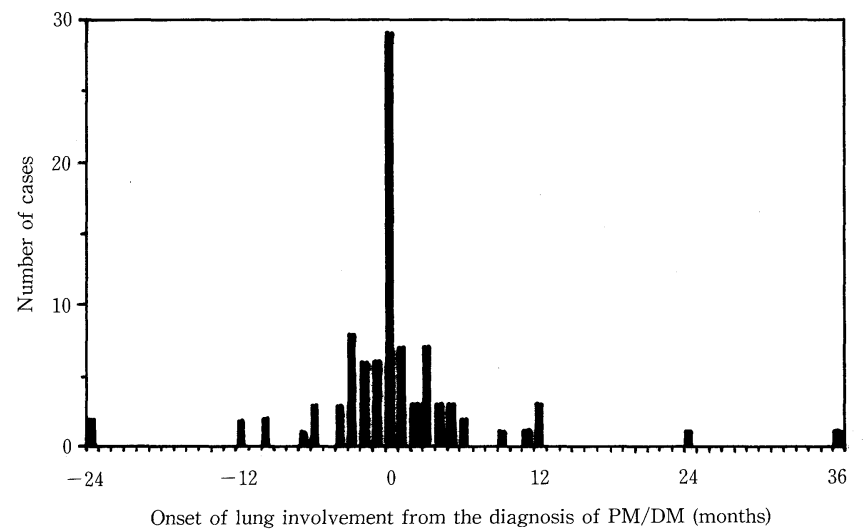

Figure 2. The chronological comparison between the onset of interstitial pneumonia and the onset of skin lesions or muscle lesions in 94 patients with polymyositis/dermatomyositis. Numbers of horizontal axis: months from the diagnosis of polymyositis/dermatomyositis to the onset of interstitial pneumonia. Most interstitial pneumonia occurred just before or just after the onset of PM/DM. In 34 cases, interstitial pneumonia preceded skin lesions and/or muscle involvement. are more common in women. Although the skin and muscles are the most commonly affected organs, pulmonary disease occurs in as high as $45 \%$ of PM/DM patients (58).

In PM/DM, the lung may be involved either primarily as in interstitial lung diseases and rarely in primary pulmonary hypertension, or it may be involved secondarily as a complication of striated muscle dysfunction leading to aspiration or to ventilatory insufficiency (58). In addition, lung disease may also occur as a sequela of the treatment of PM/DM such as in drug-induced interstitial pneumonitis and opportunistic lung infection (58).

In the present study, we demonstrated that interstitial pneumonia frequently occurred at the onset of PM/DM. Although the pathogenesis of pulmonary complications observed in PM/ DM are heterogeneous as listed above, we only evaluated cases in which the existence of interstitial pneumonia was histologically confirmed. Therefore, patients evaluated in the present study were believed to have definite interstitial pneumonia associated with PM/DM. However, since we only evalvated the histologically confirmed cases and because it is generally difficult to perform surgical lung biopsy in acute progressive cases or severely affected cases, it is possible that relatively chronic and mild cases were included in the study.

In the present study, in addition to our own 8 cases, we list patients from the reported literature. Therefore, bias of reviewing case reports should be discussed. In our 8 cases, there was no selection of patients. In addition, in the report of Schwarz et al (11) (6 cases) as well as in the report of Tazelaar et al (22) 
(15 cases), it was believed that there was no patient selection. In these reports, as observed in all of our 8 cases, interstitial pneumonia occurred before the onset of PM/DM in 4 of 6 cases reported by Schwarz et al (11) and in 2 of 15 cases reported by Tazelaar et al (22). In contrast, in the report of Ito et al, they selected 7 retrospective cases with DM accompanied by rapidly progressive interstitial lung disease (45), diffuse alveolar damage was diagnosed in all cases by autopsy. Therefore, this report had a significant bias. In addition, there might be a bias in that an aggressive form of interstitial pneumonia and patients with amyopathic DM (frequently complicated with AIP) were collected. However, even if we selectively evaluated patients with PM, the tendency for lung onset was higher compared with DM as well as amyopathic DM.

Since lung involvement was observed at the diagnosis of $\mathrm{PM} / \mathrm{DM}$ in all of the present 8 cases (including 7 preceding cases), it was suggested that the diagnosis of interstitial pneumonia had been very early in our cases compared with previously reported cases. This evidence might be a result of the early chest CT examination for the diagnosis of interstitial pneumonia in our department.

We also demonstrated that in patients with DM and amyopathic DM, skin lesions frequently occurred before the onset of interstitial pneumonia. This finding was reasonably understood because skin lesions were easily recognized by patients. In contrast, in patients with PM, lung involvement frequently occurred before the onset of muscle symptoms. It is obvious that the diagnosis of PM is uncommonly made in the early stages, the reason being i) general unfamiliarity with the condition, ii) variability in the mode of onset, iii) insidious onset of weakness simulating muscular dystrophy in many cases, and iv) the initial symptom is nonmuscular in more than one-third of the cases (59).

Since a wide range of clinical presentations is manifested by interstitial pneumonia, it should also be considered that interstitial pneumonitis was not diagnosed at the onset of PM/ DM. It is obvious that interstitial pneumonia is diagnosed with more sensitivity using a chest CT than a chest X-ray. In addition, since our cases were histologically confirmed as interstitial pneumonia, it is possible to perform histological classification, for example, UIP, NSIP, BOOP, or AIP. Among these types, UIP revealed chronic pathological changes, and therefore, cases diagnosed histologically to be UIP should be carefully evaluated. In the present study, in some cases (cases 4, 9, 15, 40, and 69), UIP was histologically diagnosed after the onset of skin and/or muscle involvement. Cases 4 (4), 9 (7), and 69 (39) were diagnosed after 12 months, case 15 (11) was diagnosed after 24 months, and case 40 (22) was diagnosed after 36 months from the onset of PM/DM. Since UIP is believed to be the pathological finding of chronic interstitial pneumonia, it was speculated that interstitial pneumonia was diagnosed very late in these cases.

The etiology and pathogenesis of interstitial pneumonia associated with PM/DM remains obscure. It is believed that the initial lung injury is immunologically mediated because of the prominent infiltration of immune effector cells observed in early lesions. The relative importance of cell-mediated immunity, cytotoxic antibodies, and immune complex injury remains unclear. Experimental evidence supports a more important role for cell-mediated than for humoral immunity in the pathogenesis of the myositis of PM/DM (58). Fata et al (36) reported that the relationship between BOOP and PM suggests that a common exogenous antigen or autoantigen may become the target of a cell-mediated immune response in the lung and the muscle. Since clinical evidence of interstitial pneumonia often precedes the clinical presentation of muscle disease, it might be important to search for specific respiratory pathogens (virus, and/or bacteria) in the pathogenesis of PM/DM associated with interstitial pneumonia.

In conclusion, our data demonstrate that pulmonary manifestation was frequently the first onset of PM/DM complicated with interstitial pneumonia.

\section{References}

1) Mills ES, Matthews WH. Interstitial pneumonitis in dermatomyositis. JAMA 160: 1467-1470, 1956.

2) Goldfischer J, Rubin EH. Dermatomyositis with pulmonary lesions. Ann Intern Med 50: 194-206, 1959.

3) Hyun BH, Diggs CL, Toone EC Jr. Dermatomyositis with cystic fibrosis (honeycombing) of the lung. Case report. Dis Chest 42: 449-453, 1962.

4) Sandbank M, Grunebaum M, Katzenellenbogen I. Dermatomyositis associated with subacute pulmonary fibrosis. Arch Dermatol 94: 432-435, 1966.

5) Weaver AL, Brundage BH, Nelson RA, Bischoff MB. Pulmonary involvement in polymyositis: report of a case with response to corticosteroid therapy. Arthritis Rheum 11: 765-773, 1968.

6) Thompson JE. Lung involvement in polymyositis. Med J Aust 1: 13321333, 1971.

7) Olsen GN, Swenson EW. Polymyositis and interstitial lung disease. Am Rev Respir Dis 105: 611-617, 1972.

8) Webb DR, Currie GD. Pulmonary fibrosis masking polymyositis. Remission with corticosteroid therapy. JAMA 222: 1146-1149, 1972.

9) Duncan PE, Griffin JP, Garcia A, Kaplan SB. Fibrosing alveolitis in polymyositis. A review of histologically confirmed cases. Am J Med 57: 621626, 1974.

10) Krain L. Dermatomyositis in six patients without initial muscle involvement. Arch Dermatol 111: 241-245, 1975.

11) Schwarz MI, Matthay RA, Sahn SA, Stanford RE, Marmorstein BL, Scheinhorn DJ. Interstitial lung disease in polymyositis and dermatomyositis: analysis of six cases and review of the literature. Medicine (Baltimore) 55: 89-104, 1976.

12) Plowman PN, Stableforth DE. Dermatomyositis with fibrosing alveolitis: response to treatment with cyclophosphamide. Proc R Soc Med 70: 738740, 1977.

13) Fernandes L, Goodwill CJ. Dermatomyositis without apparent myositis, complicated by fibrosing alveolitis. J R Soc Med 72: 777-779, 1979.

14) Hanawa M, Mabuchi T, Oeda H, Kobayashi H, Fujisawa $H$, Sumiyoshi A. A case polymyositis preceded by interstitial pneumonia - proved by open lung biopsy and serial muscle biopsies. Nihon Kyobu Shikkan Gakkai Zasshi 19: 575-580, 1981 (in Japanese).

15) Fergusson RJ, Davidson NM, Nuki G, Crompton GK. Dermatomyositis and rapidly progressive fibrosing alveolitis. Thorax 38: 71-72, 1983.

16) Schiavi EA, Roncoroni AJ, Puy RJ. Isolated bilateral diaphragmatic paresis with interstitial lung disease. An unusual presentation of dermatomyositis. Am Rev Respir Dis 129: 337-339, 1984.

17) Wasicek CA, Reichlin M, Montes M, Raghu G. Polymyositis and interstitial lung disease in a patient with anti-Jo1 prototype. Am J Med 76: 538-544, 1984. 
18) Fudman EJ, Schnitzer TJ. Dermatomyositis without creatine kinase elevation. A poor prognostic sign. Am J Med 80: 329-332, 1986.

19) Gruhn WB, Diaz-Buxo JA. Cyclosporine treatment of steroid resistant interstitial pneumonitis associated with dermatomyositis/polymyositis. $\mathbf{J}$ Rheumatol 14: 1045-1047, 1987.

20) Takizawa H, Shiga J, Moroi Y, Miyachi S, Nishiwaki M, Miyamoto T. Interstitial lung disease in dermatomyositis: clinicopathological study. $\mathrm{J}$ Rheumatol 14: 102-107, 1987.

21) Kobayashi N, Takizawa $H$, Sugiyama $H$, et al. A case of dermatomyositis which rapidly developed to respiratory failure in the presence of pneumomediastinum. Nihon Kyobu Shikkan Gakkai Zasshi 27: 848-854, 1989 (in Japanese).

22) Tazelaar HD, Viggiano RW, Pickersgill J, Colby TV. Interstitial lung disease in polymyositis and dermatomyositis. Clinical features and prognosis as correlated with histologic findings. Am Rev Respir Dis 141: 727 733, 1990.

23) Tokiyama K, Tagawa H, Yokota E, et al. Two cases of amyopathic dermatomyositis with fatal rapidly progressive interstitial pneumonitis. Ryumachi 30: 204-211, 1990 (in Japanese).

24) Lambie PB, Quismorio FP Jr. Interstitial lung disease and cryoglobulinemia in polymyositis. J Rheumatol 18: 468-469, 1991.

25) Mahler DA. Dyspnea and muscle weakness in a 65-year-old woman. Chest 102: 1875-1876, 1992.

26) Imokawa $S$, Sato $A$, Iwata $M$, et al. A case of bronchiolitis obliterans organizing pneumonia with positive anti Jo-1 antibody preceding polymyositis. Nihon Kyobu Shikkan Gakkai Zasshi 30: 914-919, 1992 (in Japanese).

27) Hsue YT, Paulus HE, Coulson WF. Bronchiolitis obliterans organizing pneumonia in polymyositis. A case report with longterm survival. J Rheumatol 20: 877-879, 1993.

28) Lohr HF, Bocher WO, Hermann E, et al. Interstitial alveolitis as early manifestation of anti-Jo-1 positive polymyositis. Z Rheumatol 52: 307 311,1993

29) Mouri M, Nambu Y, Matsui M, et al. A case of interstitial pneumonia of polymyositis-dermatomyositis with various pathological findings in open lung biopsy. Nihon Kyobu Shikkan Gakkai Zasshi 31: 629-635, 1993 (in Japanese).

30) Clawson $\mathrm{K}$, Oddis $\mathrm{CV}$. Adult respiratory distress syndrome in polymyositis patients with the anti-Jo-1 antibody. Arthritis Rheum 38: 1519-1523, 1995.

31) de Toro Santos FJ, Verea-Hernando H, Montero C, Blanco-Aparicio M, Torres Lanzas J, Pombo Felipe F. Chronic pneumomediastinum and subcutaneous emphysema: association with dermatomyositis. Respiration 62: 53-56, 1995.

32) Ozawa Y, Kurosaka D, Hashimoto N. An autopsy case of dermatomyositis with rapidly progressive interstitial pneumonia. Nihon Rinsho Meneki Gakkai Kaishi 18: 552-558, 1995 (in Japanese).

33) Nagai $Y$, Negishi M, Tomioka S, Kurosawa M. A case of polymyositis presenting histological picture of bronchiolitis obliterans organizing pneumonia with transbronchial lung biopsy specimens. Ryumachi 35: 915919, 1995 (in Japanese).

34) Grau JM, Miro O, Pedrol E, et al. Interstitial lung disease related to dermatomyositis. Comparative study with patients without lung involvement. J Rheumatol 23: 1921-1926, 1996.

35) Ikuta N, Kondoh $\mathrm{Y}$, Taniguchi $\mathrm{H}$, et al. Rapidly progressing BOOP in a patient with positive anti-Jo-1 antibody: response to corticosteroid pulse and immunosuppressant therapy. Nihon Kyobu Shikkan Gakkai Zasshi 34: 1156-1162, 1996 (in Japanese).

36) Fata F, Rathore R, Schiff C, Herzlich BC. Bronchiolitis obliterans organizing pneumonia as the first manifestation of polymyositis. South Med J 90: 227-230, 1997.

37) Kalenian M, Zweiman B. Inflammatory myopathy, bronchiolitis obliterans/organizing pneumonia, and anti-Jo-1 antibodies-an interesting association. Clin Diagn Lab Immunol 4: 236-240, 1997.
38) Shinohara T, Hidaka T, Matsuki Y, et al. Rapidly progressive interstitial lung disease associated with dermatomyositis responding to intravenous cyclophosphamide pulse therapy. Intern Med 36: 519-523, 1997.

39) Asanuma Y, Yamada $H$, Matsuda $T$, et al. Successful treatment of interstitial pneumonia with lipo-PGE1 and pentoxifylline in a patient with dermatomyositis. Ryumachi 37: 719-726, 1997 (in Japanese).

40) Kiely JL, Donohoe P, Bresnihan B, McNicholas WT. Pulmonary fibrosis in polymyositis with the Jo-1 syndrome: an unusual mode of presentation. Respir Med 92: 1167-1169, 1998.

41) Nobutoh T, Kohda M, Doi Y, Ueki H. An autopsy case of dermatomyositis with rapidly progressive diffuse alveolar damage. J Dermatol 25: 3236, 1998.

42) Satoh $S$, Hirakata $M$, Nakamura $K$, et al. Two cases of polymyositis associated with interstitial pneumonia with anti-OJ (isoleucyl tRNA synthetase) antibodies. Ryumachi 38: 534-541, 1998 (in Japanese).

43) Satomi K, Michibata T, Iizuka H, Hukuda H, Miyashita T. Recurrent pneumomediastinum in the course of interstitial pneumonia associated with dermatomyositis. Nihon Kokyuki Gakkai Zasshi 36: 984-988, 1998 (in Japanese).

44) Takahashi $\mathrm{H}$, Matsumoto $\mathrm{T}$, Abe $\mathrm{T}$, et al. A case of polymyositis with antiJo-1 antibody preceded by BOOP. Nihon Rinsho Meneki Gakkai Kaishi 21: 87-94, 1998 (in Japanese).

45) Ito M, Kaise S, Suzuki S, et al. Clinico-laboratory characteristics of patients with dermatomyositis accompanied by rapidly progressive interstitial lung disease. Clin Rheumatol 18: 462-467, 1999.

46) Itoh T, Mitsuoka S, Uji M, Matsushita H. Successful combination chemotherapy with low-dose methotrexate and steroids for dermatomyositis complicated by interstitial pneumonitis. Nihon Kokyuki Gakkai Zasshi 37: 636-640, 1999 (in Japanese).

47) Knoell KA, Hook M, Grice DP, Hendrix JD Jr. Dermatomyositis associated with bronchiolitis obliterans organizing pneumonia (BOOP). J Am Acad Dermatol 40: 328-330, 1999.

48) Takashi S, Okubo Y, Yamazaki Y, Koizumi T, Sekiguchi M. Amyopathic dermatomyositis with interstitial pneumonia: effective treatment with cyclophosphamide pulse therapy. Nihon Kokyuki Gakkai Zasshi 37: 647 651, 1999 (in Japanese).

49) Lee YH, Choi SJ, Ji JD, et al. Dermatomyositis without elevation of creatine kinase presented as bronchiolitis obliterans organizing pneumonia. Korean J Intern Med 15: 85-88, 2000.

50) Nanke Y, Tateisi M, Yamagata H, Hara M, Kamatani N. A case of amyopathic dermatomyositis with rapidly progressive interstitial pneumonia. Ryumachi 40: 705-710, 2000 (in Japanese).

51) Katzenstein AL, Fiorelli RF. Nonspecific interstitial pneumonia/fibrosis. Histologic features and clinical significance. Am J Surg Pathol 18: 136147, 1994.

52) Bohan A, Peter JB. Polymyositis and dermatomyositis (first of two parts) N Engl J Med 292: 344-347, 1975.

53) Dalakas MC. Polymyositis, dermatomyositis and inclusion-body myositis. N Engl J Med 325: 1487-1498, 1991.

54) Tanimoto K, Nakano K, Kano $S$, et al. Classification criteria for polymyositis and dermatomyositis. J Rheumatol 22: 668-674, 1995.

55) Katzenstein AL, Myers JL, Mazur MT. Acute interstitial pneumonia: A clinicopathologic, ultrastructural, and cell kinetic study. Am J Surg Pathol 10: 256-267, 1986.

56) Euwer RL, Sontheimer RD. Amyopathic dermatomyositis (dermatomyositis sine myositis). Presentation of six new cases and review of the literature. J Am Acad Dermatol 24: 959-966, 1991.

57) Sayers ME, Chou SM, Calabrese LH. Inclusion body myositis: analysis of 32 cases. J Rheumatol 19: 1385-1389, 1992.

58) Dickey BF, Myers AR. Pulmonary disease in polymyositis/dermatomyositis. Semin Arthritis Rheum 14: 60-76, 1984.

59) Pearson CM. Polymyositis and dermatomyositis. in: Arthritis and Allied Conditions, McCarty DJ, Ed, 9th ed, Lea \& Febiger, Philadelphia, 1979: 742-761. 